\title{
Differentiation of rat intestinal epithelial cells is induced by organotypic mesenchymal cells in vitro
}

\author{
A STAIIMACH, U HAHN: H J MERKER: E ( HAHN: ANI) EO RIECKEN \\ From the 'Free University of Berlin, Klinikum Steglitz Medical School, Department of Medicine. Division of \\ (iastroenterology, Berlin, IRR(;. Thomas Jefferson University, Jefferson Medical College, Departme'nt of \\ Medicine, Division of (iastroenterology and Hepatology, Philadelphia, USA, and Free University of Berlin. \\ Department of Anatomy, Berlin, IRR
}

scinisk Stromal-epithelial interaction is a potent driving force in the developing intestinal mucosa which ensures tissue specific cellular differentiation. The mechanisms involved are relevant to tissue renewal in adult organs yet they have not been elucidated because of the lack of appropriate in vitro models. In this study, we have investigated the interaction between intestinal mesenchymal and epithelial cells at the cellular level in vitro. Fetal rat intestinal epithelial cell colonies explanted in vitro on the 15th day of gestation, which failed to mature in plain monocultures, were reassociated in coculture with three different types of mesenchyme: fetal skin, gastric and intestinal mesenchyme. Only fetal epithelial cells cocultured with intestinal (homologous) mesenchyme acquired definite signs of differentiation within three to six days. These primitive epithelial cells were shown by electronmicroscopy to become highly polarized, connected by tight junctions and covered with a regular brush border. Three brush border enzymes were strongly expressed in homologous cocultures and their activity was sensitive to dexamethasone. In contrast, fetal epithelial cells cocultured with skin or stomach derived mesenchyme under identical conditions failed to differentiate in vitro: they remained flat, unpolarised and expressed only low enzyme activity. The unique potential of the small intestinal mesenchyme to promote intestinal epithelial differentiation is discussed.

\begin{abstract}
The fundamental thesis by Grobstein that, during fetal life, the mesenchyme molds the epithelium into its final form and modulates its specific functions has been verified for many different organs.' Organs in which the epithelium is derived from the embryonic visceral endoderm like the thymus, trachea, pancreas and the intestinal mucosa represent particularly fascinating examples of epithelial-mesenchymal interactions. During a defined gestational period, the primitive endoderm develops into the organspecific (parenchymal) types of epithelium as it interacts with its respective (stromal) mesenchyme at the anatomical site of the future organ. Experimental confirmation of these developmental patterns has been obtained through studies with recombined and
\end{abstract}

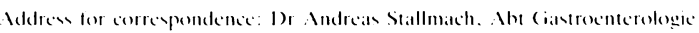

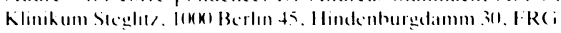

sceptedfor publacitons Norember less grafted tissues in vivo, and. more recently, tissuc culture studies in vitro. $\therefore$

Maturation of the intestinal endoderm (primary fetal intestinal epithelium) as a function of mesenchymal activity was first suggested by an electronmicroscopic analysis of the developing rat gut." To test this hypothesis, primitive endoderm associated with various kinds of mesenchyme was grafted under the kidney capsule of adult rats, thus permitting fetal epithelial-mesenchymal interactions to take place under the systemic influenes of the adult organism. These studies emphasize a strong potential for the intestinal mesenchyme to promote epithelial cytodifferentiation." "They cannot, however, be extended to elucidate the biochemical mechanisms involved. The importance of systemic factors like hormones and circulating growth factors is difficult to distinguish under those circumstances. Also, the contribution of connective tissue cells versus extra- 
cellular matrix components to mucosal morphogenesis cannot be investigated. It is thus evident that simpler and preferably in vitro models for endodermal differentiation would alleviate such difficulties.

Several successful attempts have been reported where endodermal cytodifferentiation was recognised in vitro. While we have recently shown the influence of mesenchyme on endodermal polarisation and basement membrane formation in vitro by documenting the fate of fetal jejunal explant cultures," others have reported on the general importance of vital mesenchyme for intestinal epithelial differentiation cocultures and in organ cultures. ${ }^{121:}$

The issue of organspecificity, however, of the intestinal mesenchyme in promoting endodermal maturation has remained controversial. Therefore, the aim of this study was to observe and compare small intestinal epithelial differentiation under the influence of intestinal versus heterologous mesenchyme using carefully standardised culture conditions. In addition, the effect of a glucocorticoid hormone (dexamethasone) on epithelial development in these cocultures was investigated.

\section{Methods}

PRIEPARATION OF TISSUIS

Primary cells

Timed fetal Wistar rats were obtained by hysterectomy precisely on day 15 of gestation. The appearance of the vaginal plug as evidence of fertilisation was designated day (). The small intestine of the fetal rats was removed at $4^{\circ} \mathrm{C}$ and immediately placed into Dulbeces modified Eagles medium containing 4.5 $\mathrm{g} /$ glucose (Bochringer Mannheim, West Germany) to which $(0.0) 3 \mathrm{mg} / \mathrm{ml}$ collagenase $(156 \mathrm{U} / \mathrm{mg}$ CSP II, Worthington, USA) had been added. The intestines were incubated at $36^{\circ} \mathrm{C}$ under $8 \% \mathrm{CO}_{2}$ in air for 9() minutes. The endoderm was then mechanically separated from the surrounding mesenchyme under a dissecting microscope. Endodermal cell clusters were obtained by cutting the endodermal tube with fine scalpels into fragments of $0.5 \mathrm{~mm}$ side length. The remaining mesenchyme was used as stated below.

Primary fetal skin explants from the dorsal integumentum and primary mesodermal explants of the gastric or intestinal mucosa were prepared in parallel on the 15 th day of gestation. $1 \times 1 \mathrm{~mm}$ fragments of skin mesenchyme, and intestinal and gastric mesenchyme free of endoderm, were explanted onto $35 \mathrm{~mm}$ plastic petri dishes. The mesenchymal cells vigorously proliferating from these explants could be subcultured after five to six days by treating them with $0.25 \%$ trypsin. $0.05 \%$ EDTA (Bochringer Mannheim, West Germany) for five minutes. Becautse of their density dependent growth, mesenchymal cells from the gut had to be seeded at more than $15(4)()$ cells/cm: while skin mesenchymal cells did not exhibit unusual density dependency. (ell counts were done by counting representative aliquots of eell suspensions in a Neubauer chamber.

All mesenchymal eells were used either after the first or second passage in parallel. Frequency of medium exchange was not crucial in establishing confluent monolayers and was performed routincly every three to four days.

\section{Cocultures of epithelial and mesenchymal cells}

Endoderm was prepared as described above. Endodermal clusters were then seeded either on top of the confluent mesenchymal monolayers or into albumin coated or plain plastic petri dishes with (1.08 $\mathrm{ml} \mathrm{medium} / \mathrm{cm}$, so that the endodermal cell layer was barely covered with medium to facilitate attachment. After 24 hours, the medium was exchanged and $1-2 \mathrm{ml}$ of fresh medium were added to the now adherent cocultures. A total of over $200(0)$ endodermal microexplants from over 28 litters of eight to 12 rat embryos each were prepared and followed up in vitro. Follow up included photodocumentation of each endodermal colony for planimetric evaluation and histochemical detection of brush border enzyme activity or, alternatively, transverse electron microscopy as described below.

\section{Media}

Endodermal cell cultures were cultivated on plastic in Dulbecess modified Eagles medium (Biochrome, West Germany) plus $10 \%$ fetal calf serum, $4 \mathrm{mmol}$ glutamine, $50 \mu \mathrm{g} / \mathrm{ml}$ ascorbic acid, $50 \mathrm{U} / \mathrm{ml}$ penicillin and $50 \mu \mathrm{g} / \mathrm{ml}$ streptomycin (reagents from Sigma, West Germany) at $36^{\circ} \mathrm{C}$ in $8 \% \mathrm{CO}_{2}$ in air. Primary mesenchymal cultures were initiated in the same medium but containing $15 \%$ fetal calf serum. Cocultures of mesenchyme and endoderm received medium plus $10 \%$ fetal calf serum.

To determine the effect of dexamethasone on epithelial cytodifferentiation, this hormone was added to the medium at a final concentration of $1(0)$ nmol at the start of the endodermal-mesenchymal coculture. In mesenchymal monocultures, the medium was supplemented with the hormone at the same concentration.

IESTIMATION OF ( IEIT. PROIIFIERATION IN VITRO The only way to estimate the proliferation of the endodermal cells of individual colonies without harvesting them, which would have impeded the 
follow up of each colony, was to document the size of each colony every 24 hours by phase contrast microscopy and to calculate the increase in size planimetrically from the film. Proliferation was thus defined as the increase in total area covered by an endodermal colony in 24 hours. A Zeiss 35 inverted microscope equipped with a Canon camera and Kodak 400 Ektachrome or Ilford 5HP films were used throughout.

Proliferation of skin and intestinal mesenchymal cells was measured by allowing them to attach to several $25 \mathrm{~cm}^{2}$ flasks at a seeding density of 20000 cells $/ \mathrm{cm}^{2}$ in medium with and without $100 \mathrm{nmol}$ dexamethasone. After 24, 48, 72, and 96 hours identical square fields of approximately $1 \mathrm{~mm}^{2}$ (four squares per flask) were photographed and the number of cells was counted (150-300 cells $\left./ \mathrm{mm}^{2}\right)$. The average increase in cell number was calculated from the mean increase of all fields.

HISTOCHEMICAL TECHNIQUES

The presence of alkaline phosphatase, lactase and alpha-glucosidase in the endodermal cells was determined histochemically after two, four, and six days in vitro. The cocultures were rinsed with physiological saline, quick frozen at $-70^{\circ} \mathrm{C}$ and stained according to Gutschmidt et al. ${ }^{14}$ For controls, unfixed cryostat sections of newborn rat small intestine were routinely developed in parallel which displayed the expected colour reaction confined to the brush border membrane of the villus enterocytes.

A grading system for the expression of brush border enzyme activity in endodermal cell colonies ranging from negative to strongly positive was established: $-:<50 / 1000$ positive cells $(<5 \%) ;+: 50-99 /$ 1000 positive cells $(5-<10 \%) ;++: 100-499 / 1000$ positive cells $(10-<50 \%) ; \quad+++: 500-899 / 1000$ positive cells $(50-<90 \%) ;++++: 900-1000 / 1000$ positive cells $(90-100 \%)$.

Three individual investigators performed the grading of the stained colonies either directly at the microscope or from films without prior knowledge of the type of coculture under investigation.

EI.ECTRON MICROSCOPY

For transmission electron microscopy, cocultures and endoderm were grown on Thermonox ${ }^{(k)}$ (Miles Laboratories) slides, fixed at the appropriate intervals in $1 \%$ glutaraldehyde containing $1 \%$ tannin in $0.1 \mathrm{M}$ phosphate buffered saline, postfixed in $1 \%$ buffered osmium tetraoxide and embedded in Mikropal $^{\mathrm{R}}$ as described. ${ }^{14}$

STATISTICAI. ANALYSIS

Statistical analysis was performed using the MannWhitney U test (for unmatched pairs).

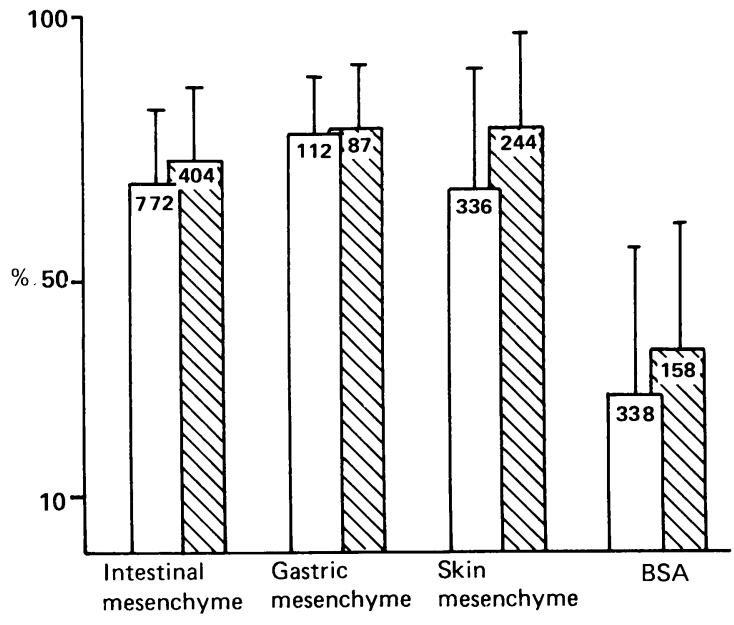

Fig. 1 Rate of attachment (\%) of endodermal fragments (resected on the 15th day of gestation) to confluent mesenchymal monolayers derived from different organs and to albumin-coated petri dishes. The endodermal explants were incubated for 24 hours in the presence or absence of dexamethasone after which the petri dishes were rinsed to eliminate all non-adherent endodermal cells. The total number of firmly attached and spread endodermal colonies was then determined by phase contrast microscopy. Open bars: attachment rate of endodermal fragments incubated in normal medium (mean (I SD)). Striped bars: attachment rate of endodermal fragments incubated in normal medium +100 nM dexamethasone (mean (ISD)). The numbers at the top of the bars indicate the total number of explanted endodermal fragments in each group.

\section{Results}

INITIATION OFENDODERMAL EXPLANTS AND COCULTURES

Within the first 12-24 hours in vitro, the endodermal explants adhered to the plastic petri dishes or to the mesenchymal monolayers and began to spread. A significantly different affinity to the various substrates was observed, however. While only maximally $27 \%$ of all endodermal fragments attached to untreated or albumin coated surfaces, over $70 \%$ of all endodermal explants stabily associated with intestinal and gastric mesenchyme and $61 \%$ with skin mesenchyme. The difference in the attachment rates between the respective mesenchymes was statistically not significant. Addition of dexamethasone to the culture medium slightly increased the efficiency of this process in all groups (Fig. 1). In a separate set of experiments, we found that the presence of $10 \%$ fetal calf serum enhanced the attachment about twofold on intestinal mesenchyme compared to serum free medium. Addition of more than $20 \%$ fetal calf serum reduced the affinity again and at $50 \%$, toxicity 

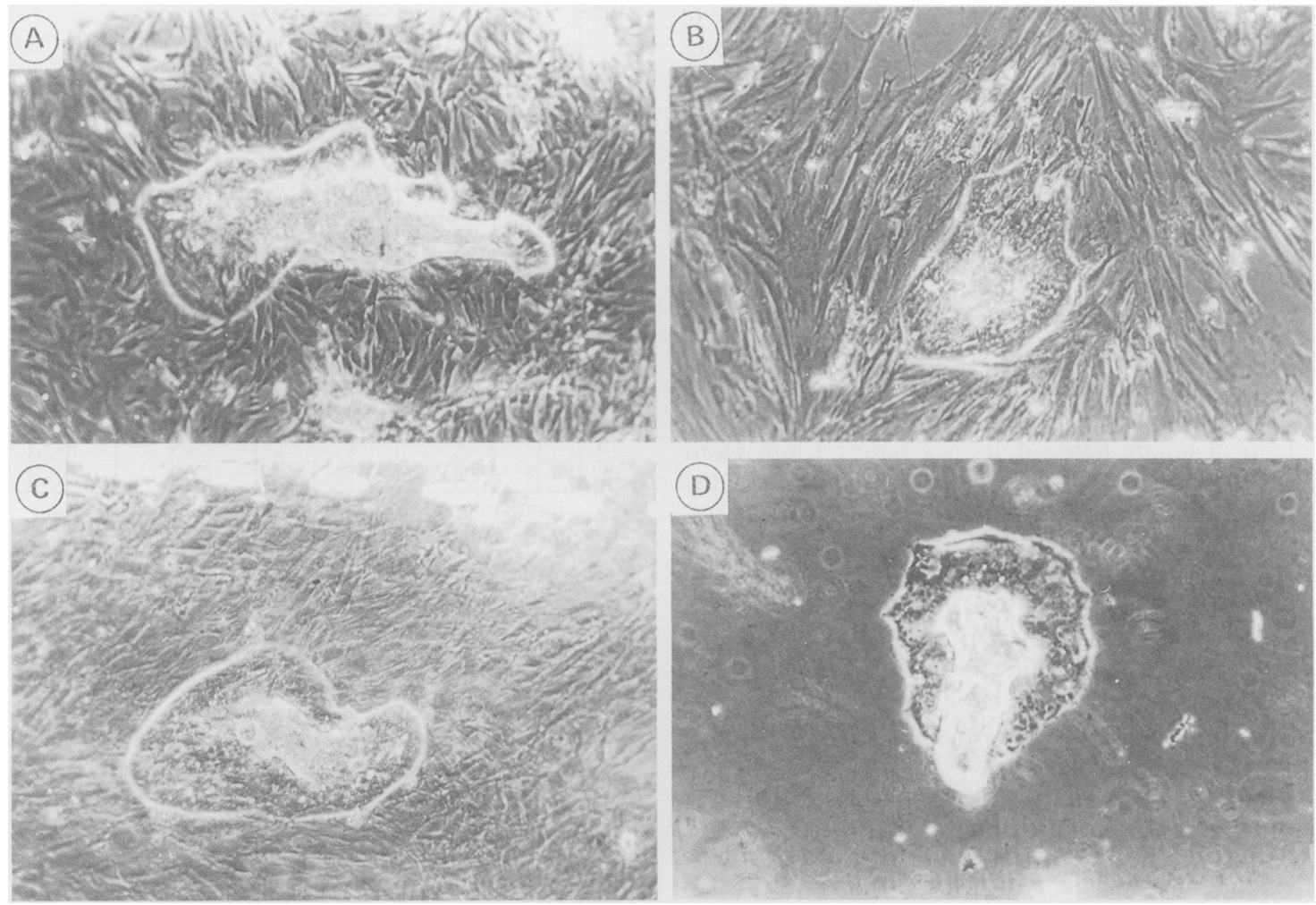

Fig. 2 Phase contrast microscopy of the endodermal colonies after 24 hours on different mesenchymal monolayers and bovine serum albumin. (A): endoderm and small intestinal mesenchyme. (B): endoderm and gastric mesenchyme.

(C): Endoderm on skin mesenchyme. (D): endoderm on albumin. Note that the different types of mesenchymal cells convey a different morphology while the initial endodermal outgrowth is very similar on all substrates.

to both endoderm and mesoderm became apparent (data not shown).

No difference in the morphology of the endodermal cells was noted as they established their primary contact with intestinal (Fig. 2A), gastric (Fig. 2B), and skin mesenchyme (Fig. 2C) or with albumin within the first 24 hours. In all instances, the outgrowth and reorganisation of the primary epithelial cells from the original endodermal fragment lead to an oval, almost flat monolayer of epithelial cells within the first day in vitro.

PROI.IFERATION AND MORPHOIOCGYO

IENDODERMAI. CEILIS COCUITURII) WITH

MESENCHYMAL CELLLS

\section{In normal medium}

Although the initial phase of endodermal outgrowth of the explants was similar on all mesenchymes and on albumin, a remarkably different evolution became obvious as the cocultures progressed in vitro.
While endoderm attached to the albumin coated petri dish reached its maximal expansion by day 3 in vitro (().87 $\mathrm{mm}^{2}$, (SD 0.29$)$ ), the endodermal cells cocultured with mesenchyme continued to proliferate. Of the three different types of mesenchyme tested, skin mesenchyme supported endodermal colony expansion until the fifth day in vitro, while gastric and intestinal mesoderm promoted endodermal growth only until the fourth day in vitro. The average maximal size of the area covered by the endodermal epithelium measured $(0.91 \mathrm{~mm}$ (SI) (0.53) on intestinal mesenchyme (Fig. 3A), $1 .(18 \mathrm{~mm}$ (SI) ().35) on gastric mesenchyme (Fig. 3B) and 2.21 $\mathrm{mm}^{2}$ (SD 0.55$)$ on skin mesenchyme $(p<0.05)$ (Fig. $3 C)$. Thus, the increase in colony size of intestinal cocultures was very similar to that of epithelial monocultures on albumin. These colonies averaged approximately $(1.9 \mathrm{~mm}$ (Fig. 3D), which represents less than half the size of skin mesenchyme cocultures.

At the time when endodermal expansion is greatest - that is, on the fourth to fifth day in vitro. 

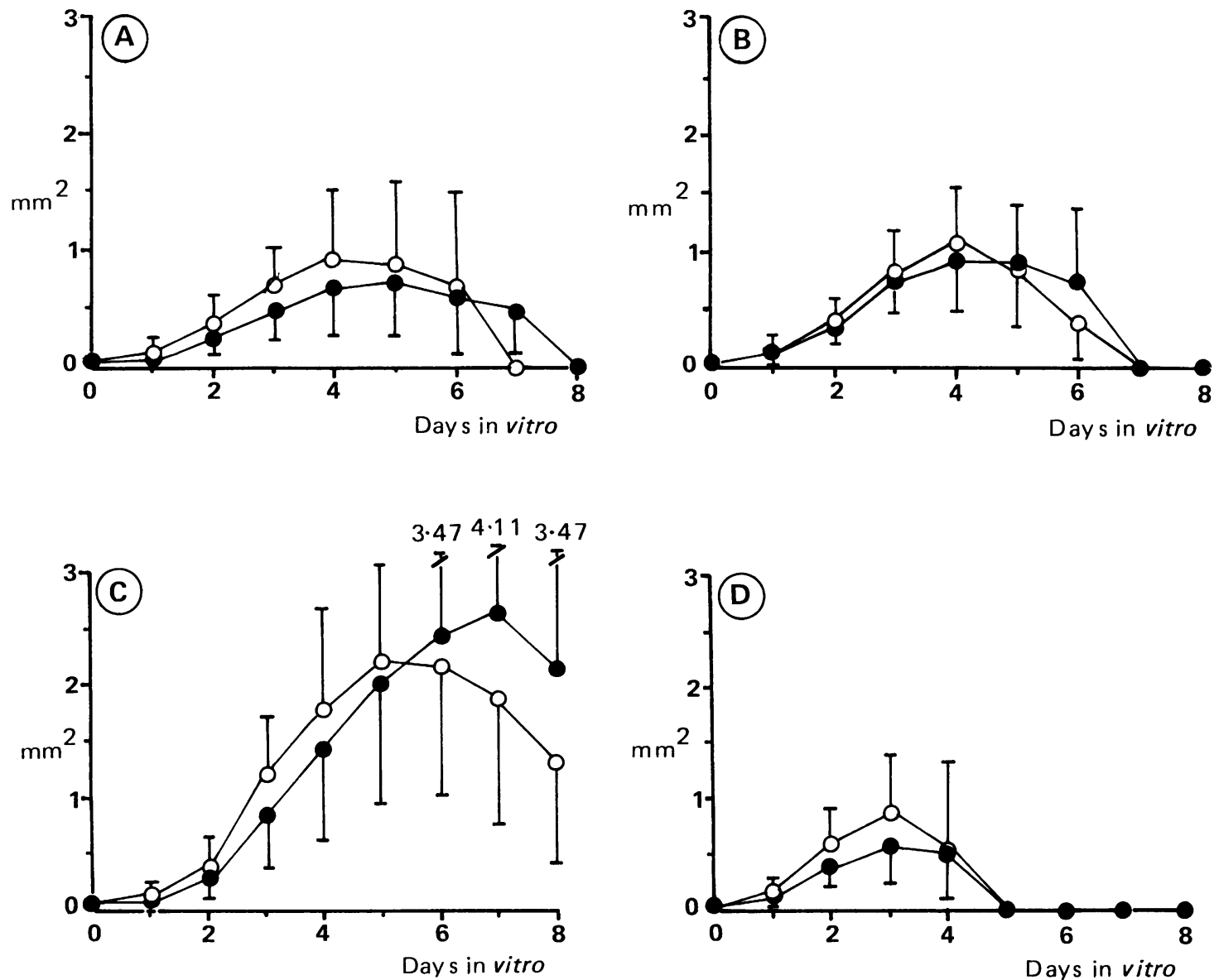

Fig. 3 Planimetric calculation of the size of individual endodermal colonies cocultured with (A) small intestinal mesenchyme, $(B)$ gastric mesenchyme, $(C)$ skin mesenchyme, and $(D)$ on albumin during the entire culture period. The values are real size values expressed in $\mathrm{mm}^{2}(1 S D)$. - : cocultures in normal medium. $\bigcirc-\bigcirc$ : cocultures in normal medium $+100 \mathrm{nM}$ dexamethasone. The hormone supplemented medium supports endodermal survival in vitro on all substrates but has no significant effect on endodermal colony expansion.

interesting variations in cell morphology were observed (Fig. 4). Endodermal cells cultured on albumin-coated plastic retained a similar aspect throughout the culture period. They formed a monolayer of large, flat epithelial cells resembling the endodermal outgrowths in mucosal explant cultures and intestinal epithelial cells of established cell lines. "10 17 There was no morphological difference between centrally and peripherally located cells. After the third day in vitro, these colonies quickly deteriorated and detached (Fig. 4D).

In contrast, endodermal colonies placed on top of confluent intestinal mesenchyme began to exhibit a gradient of cell density within the now circular explants after the third day (Fig. 4A). The innermost cells became tightly packed and very little cytoplasm was recognisable between the nuclei. On top of the endoderm small, opaque granules were shed into the medium. The borderline to the mesodermal cells remained well defined for at least six days in vitro, after which slow penetration of the mesenchymal cells disrupted the colonies. By eight to nine days in vitro the endodermal cells were completely overgrown by mesenchymal cells.

Endoderm recombined in vitro with gastric mesenchyme resembled the homologous cocultures morphologically at the level of phase contrast microscopy (Fig. 4B). Centrally located cells, however, 

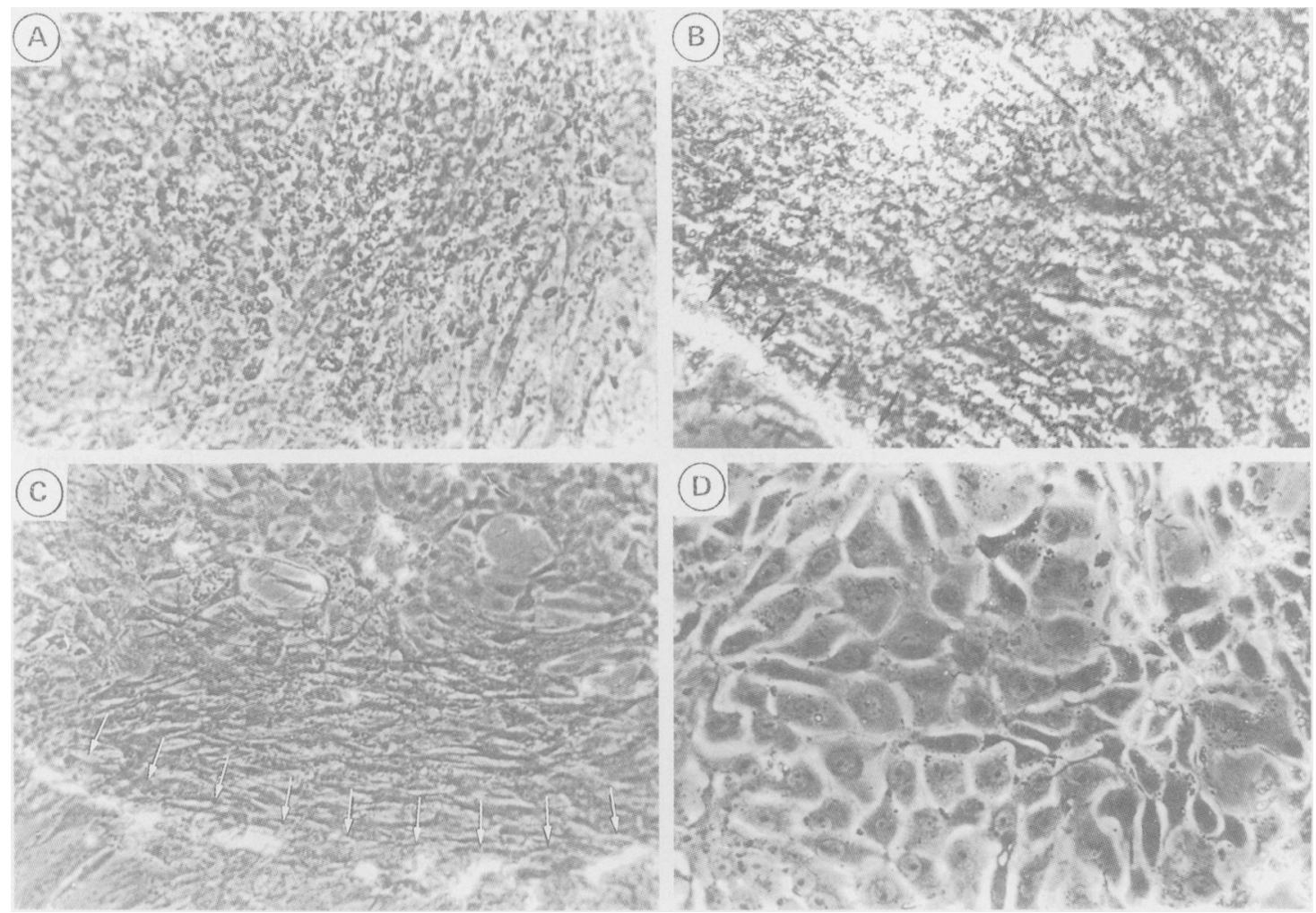

Fig. 4 Small intestinal endodermal colonies of the 15th day of gestation cocultured with different mesenchymal substrates as seen by phase contrast microscopy. $(A)$ : cocultured with intestinal mesenchyme for five days, $(B)$ : cocultured with gastric mesenchyme for five days, $(C)$ : cocultured with skin derived mesenchyme for five days, (I)): cultured on albumin for four days. The arrows indicate the border of the endodermal colony which is penetrated by skin fibroblasts in (C), while the endodermal colony border on intestinal mesenchyme is well preserved.

lacked the tightly packed organisation as described above. The endodermal colonies grew to approximately the same size. It is noteworthy that the striking difference between gastric and intestinal mesenchymal cocultures as demonstrated below at the ultrastructural level and in terms of brush border enzyme activity was not conspicuous by phase contrast microscopy of the endodermal cells.

Skin mesenchyme apparently induced the greatest proliferation rate of the endoderm in vitro (Fig. 4C). By the fifth day in vitro, individual colonies had expanded to a size more than twice as large as on albumin coated dishes. This was accompanied by a uniform aspect of the endodermal cell colonies indicating no centrifugal gradient of cell density. After four to five days, skin fibroblasts aggressively began to penetrate the endodermal cell layer from underneath and at its border leading to an irregular borderline and finally to the dissolution of the endoderm within 48 hours. The endodermal cells did not detach into the medium during this process, but were completely overgrown by the dermal fibroblasts.

\section{In medium containing $100 \mathrm{nmol}$ dexamethasone}

Addition of $100 \mathrm{nmol}$ dexamethasone to the culture medium only slightly modified the attachment rate of the endodermal fragments to various substrates (Fig. 1). The continued presence of this hormone in the cocultures reduced the expansion of endodermal colonies on plastic, intestinal and gastric mesenchyme during their growth phase (Figs 3A, B, D). Dexamethasone prolonged the survival of endodermal colonies on thee substrates by approximately one day. The hormone tended to increase the expansion of endodermal colonies on skin mesenchyme measurably but this did not reach statistical significance (Fig. 3C). 


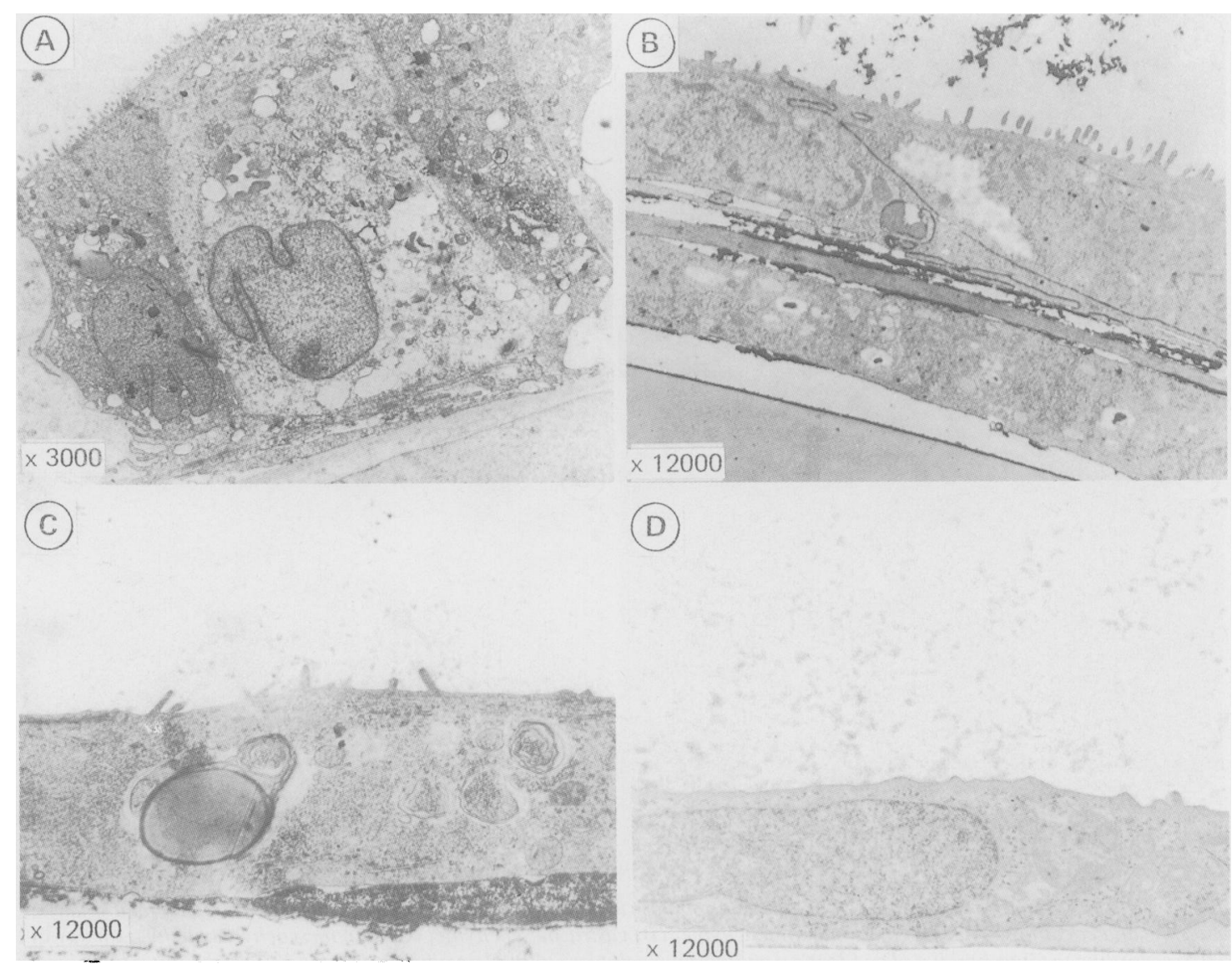

Fig. 5 Transmission electron microscopy of the central area of endodermal colonies cocultured with different mesenchymal monolayers after five days in vitro. $(A)$ : endoderm cocultured with intestinal mesenchyme; $(B)$ : endoderm on gastric mesenchyme; (C): endoderm on skin mesenchyme; $(D)$ : endoderm on albumin after four days in vitro. Note the higher magnification in $(B),(C)$, and $(D)$ versus $(A)$. Only the intestinal mesenchyme induces polarization and the formation of tight junctions in the endodermal cell layer.

To test the influence of this hormone on the individual proliferation rate of skin and intestinal mesenchymal cells they were treated with the same dose of dexamethasone. During the log phase of population growth, dexamethasone decreased the proliferation rate markedly in intestinal mesenchymal cell cultures: over 24 hours, cell numbers increased only by $17 \%$ in hormone-supplemented medium versus $41 \%$ in normal medium. Skin derived mesenchymal cells were less sensitive to the hormone as their population increase was reduced from $63 \%$ to $51 \%$ in the presence of dexamethasone.

\section{FI. ICTRON MICROSCOPYOF ENDODERMAI.}

COCUITURES

Transverse sections cut through the centre and the periphery of endodermal colonies cultured on intestinal, gastric and skin mesenchyme and analysed by electron microscopy impressively showed the differential effect of the respective mesenchymal tissues (Fig. 5).

Endodermal cells explanted onto skin mesenchyme were flat and unpolarised even in the middle of the colonies. Very few microvilli evoked the specific origin of the epithelial cells. There were only few gap junctions and no signs of heterotypic differentiation. The interface in these cocultures was characterised by the massive deposition of cross striated collagen and amorphous material. Specialised cell-cell junctions were very scarce. Skin mesenchymal cells were not aligned in parallel to the overlying epithelium. They did not display different 


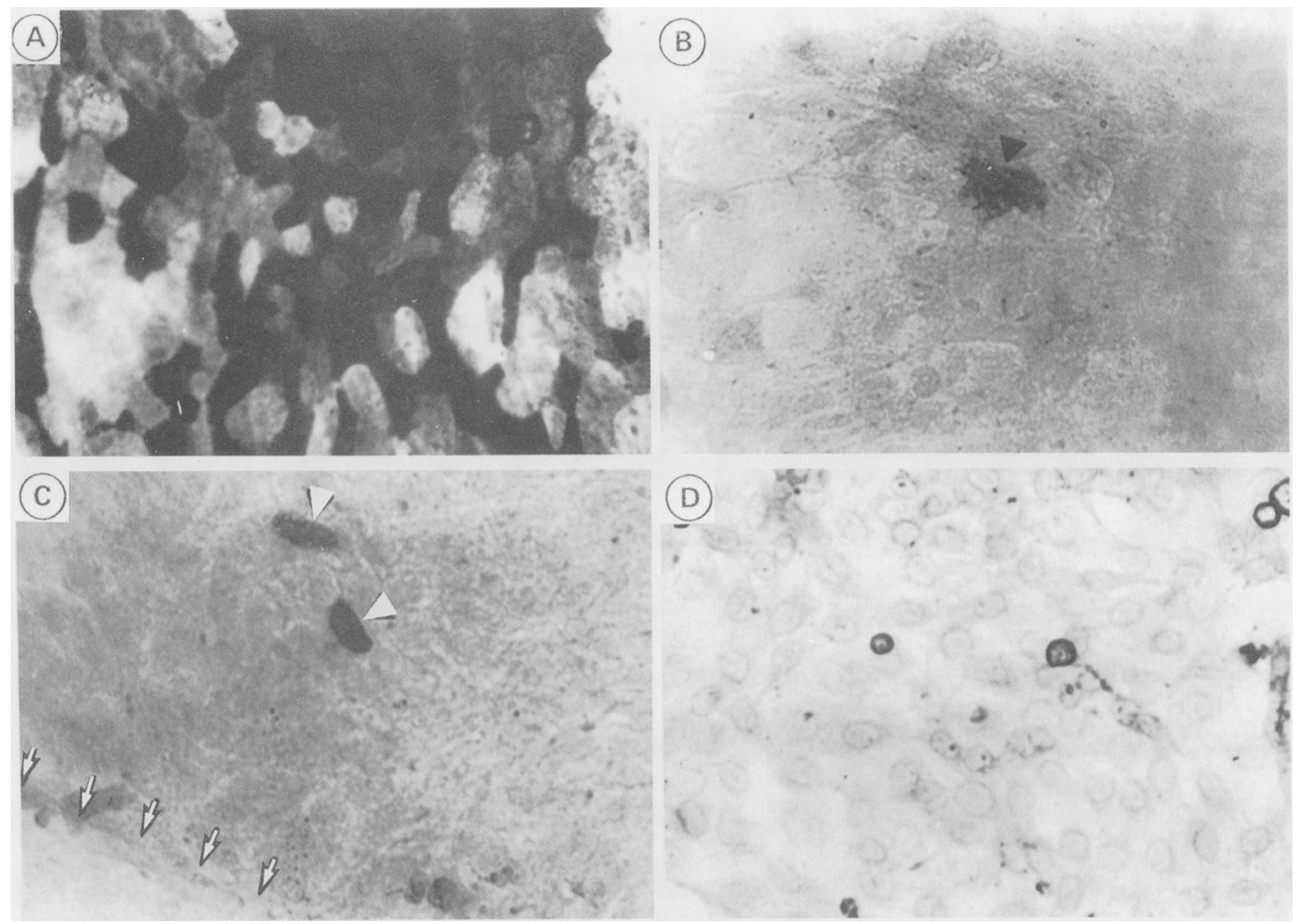

Fig. 6 Histochemical demonstration of alkaline phophatase in endodermal cell colonies derived from 15 day fetal small intestine and cocultured with $(A)$ intestinal mesenchyme, $(B)$ gastric mesenchyme, $(C)$ skin mesenchyme on the sixth day in vitro according to Gutschmidt. ${ }^{\prime+}(D)$ : Identical endodermal colonies cultured on albumin-coated petri-dishe's after four days in vitro. Only the homologous coculture gives rise to uniformly alkaline phosphatase positive epithelial cells within the endodermal colony centre which is located at the top $(A)$.

features amongst themselves and appeared as a homogenous population of fibroblasts. We did not observe a typical basement membrane underneath the epithelial cells (Fig. 5C).

The endoderm covering gastric mesenchyme was of slightly greater height and there were more, but very irregular microvilli on the upper surface (Fig. 5B). Interestingly, in some of the endodermal cells electron lucent, globular inclusions were detected which probably resemble fat vesicles. Similar vesicles have been described in guinea pig gastric mucus cell monolayers in vitro. ${ }^{\text {in }}$

In contrast, endodermal cells cocultured with intestinal mesenchyme appeared completely polarised in the centre of the colony (Fig. 5A). They were covered with a regular, though low brush border, connected by tight and intermediate junctions and their nucleus was located in the lower half of the cells and the Golgi apparatus occupied the middle and upper half of the cells. The interface of endoderm and intestinal mesenchyme was characterised by numerous cell-cell contacts and small amounts of connective tissue material. A basement membrane was not present throughout, but small stretches of authentic basement membrane were found along the basal plasma membrane of the centrally located endodermal cells. Towards the periphery of the colony, endodermal cells were lower and carried fewer microvilli. Goblet or endocrine cells could not be identified in any type of coculture.

In homologous recombinations of endoderm and mesenchyme - that is, intestinal mesenchyme with jejunal endoderm, a rather steep gradient established itself centrifugally. Comparison of vertical cell diameters in the colony eentres revealed a four fold increase in the height of entrally located epithelial 
cells cultured on intestinal mesenchyme versus epithelial cells in the periphery of the same colonies. Heterologous mesenchymal cocultures did not induce such a gradient as the central cells retained their flat, unpolarised phenotype. Thus, the vertical epithelial cell diameter in centrally located cells on intestinal mesenchyme was calculated to have increased eight-fold over their counterparts on skin and gastric mesenchyme. Note the four times smaller magnification in Fig. 5A versus Fig. 5B, C, and D.

\section{EXPRESSION OF BRUSH BORDER ENZYMES IN}

ENDODERMAL CELLS IN COCULTURES

The activity of brush border enzymes is generally regarded as a good indicator of intestinal epithelial maturation because in situ, a gradient of enzyme activity exists along the crypt-villus axis with the maximum activity residing in the microvillus membranes of the most mature epithelial cells, the villus enterocytes. ${ }^{1920}$ We therefore studied the expression of three representative brush border enzymes (alkaline phosphatase, alpha-glucosidase and lactase) in the different endodermal/mesenchymal cocultures. A grading index was applied ranging from negative $(-)$ to strongly positive $(++++)$.

Alkaline phosphatase activity in endodermal colonies on plastic remained negative (less than five positive cells $/ 100$ cells) throughout the culture period (Fig. 6D). In combination with skin and gastric mesenchyme, the frequency of alkaline phosphatase positive cells slowly increased to reach grade $+(5 \%-$ $10 \%$ positive cells) by the sixth day in vitro (Fig. $6 \mathrm{~B}$, C). In contrast, endodermal cells cultured on intestinal mesenchyme began to express strong alkaline phosphatase activity within three days in vitro. After six days, $50-90 \%$ of all endodermal cells were intensively stained for this enzyme (grade +++ ) (Fig. 6A). Enzyme activity was always most pronounced in the colony centres while it retained a mosaique pattern among the peripheral cells (Fig. 6A).

In each group of explants, the range of enzyme activity was rather variable. This is a reflection of the proximal-distal gradient of development during intestinal organogenesis when the proximal small intestine acquires mucosal maturation sooner than the distal parts. An approximately 24 hour lag period prevails in ileal segments in vitro compared with duodenal segments (unpublished observations). In this study we did not separate the endodermal fragments according to their original location and were thus able to appreciate the conservation of the gradient in vitro. For comparison of enzyme activity, however, we included only the endodermal colonies with maximal expression of the respective enzyme in each experiment. Over 50 explants of each type of recombination were evaluated for each enzyme (Fig. 6 and Table).

The effect of supplementation of the medium with dexamethasone was remarkable (Table). Dexamethasone distinctly enhanced the expression of alkaline phosphatase in homologous cocultures so that after four and six days these cultures were upgraded on the index. Dexamethasone did not, however, evoke enhanced enzyme expression in heterologous cocultures. Even after six days, we failed to detect any difference in enzyme expression between colonies cultured in normal medium and hormone supplemented medium. In homologous cocultures, histochemical detection of lactase and alpha-glucosidase depended entirely on the presence of dexamethasone in the medium. Under those conditions, lactase-positive epithelial cells appeared quite suddenly after four days in the centre of the colonies. Over the next 48 hours, more and more central cells acquired lactase positivity (grade ++ , see Table). Alpha-glucosidase became apparent only after six days in the presence of dexamethasone. In normal embryogenesis lactase activity also precedes the appearance of alpha-glucosidase by 48 hours. ${ }^{21}$

Heterologous cocultures, however, remained insensitive to dexamethasone with respect to lactase and alpha glucosidase activity so that even after six days of continuous hormone treatment no increase in the number of enzyme-positive cells was appreciable (Table).

Table Expression of brush border enzymes in endodermall mesenchymal cocultures

\begin{tabular}{|c|c|c|c|c|c|}
\hline \multirow[b]{2}{*}{ Substrate } & \multirow[b]{2}{*}{ Enzyme } & \multicolumn{2}{|c|}{4 days } & \multicolumn{2}{|l|}{6 days } \\
\hline & & $N M$ & $+D X$ & $N M$ & $+D X$ \\
\hline Albumin & $\begin{array}{l}\text { AP } \\
\text { LAC } \\
\text { GLUC }\end{array}$ & $\begin{array}{l}- \\
- \\
-\end{array}$ & $\begin{array}{l}- \\
- \\
-\end{array}$ & & \\
\hline $\begin{array}{l}\text { Intestinal } \\
\text { mesenchyme }\end{array}$ & $\begin{array}{l}\text { AP } \\
\text { LAC } \\
\text { GLUC }\end{array}$ & $\begin{array}{l}++ \\
- \\
-\end{array}$ & $\begin{array}{l}+++ \\
+ \\
-\end{array}$ & $\begin{array}{l}+++ \\
- \\
-\end{array}$ & $\begin{array}{l}++++ \\
++ \\
+\end{array}$ \\
\hline $\begin{array}{l}\text { Stomach } \\
\text { mesenchyme }\end{array}$ & $\begin{array}{l}\text { AP } \\
\text { LAC } \\
\text { GLUC }\end{array}$ & $\begin{array}{l}- \\
- \\
-\end{array}$ & $\begin{array}{l}- \\
- \\
-\end{array}$ & $\begin{array}{l}+ \\
- \\
-\end{array}$ & $\begin{array}{l}+ \\
- \\
-\end{array}$ \\
\hline $\begin{array}{l}\text { Skin } \\
\text { mesenchyme }\end{array}$ & $\begin{array}{l}\text { AP } \\
\text { LAC } \\
\text { GLUC }\end{array}$ & $\begin{array}{l}- \\
- \\
-\end{array}$ & $\begin{array}{l}- \\
- \\
-\end{array}$ & $\begin{array}{l}+ \\
- \\
-\end{array}$ & $\begin{array}{l}+ \\
- \\
-\end{array}$ \\
\hline
\end{tabular}

Bruch border enzymes alkaline phosphatase (AP), actase (LAC), and alpha-glucosidase (GLUC) were determined histochemically in endodermal-mesenchymal cocultures after four and six days in vitro. The cultures were either maintained in normal medium (NM) or in medium containing $100 \mathrm{nmol}$ dexamethasone $(+\mathrm{DX})$. The number of stained (positive) cells in the centre of each colony was counted. Enzyme activity was graded using an index of - (negative $=<5 \%$ stained cell) to ++++ (strongly positive $=90-100 \%$ stained cells $)$. For details see Methods. 


\section{Discussion}

Plain monocultures of small intestinal epithelial cells of the fetal rat, removed on the 15 th day of gestation, are unable to acquire any features of differentiation in vitro. The results presented in this study indicate that the fate of these epithelial cells in vitro could be fundamentally reversed to resemble their normal development in utero if they became vitally associated with small intestinal mesenchyme. Mesenchyme of the same embryonic age but from other organs was ineffective.

Reassociated with primary small intestinal mesenchyme in vitro, the endodermal cells were morphologically and functionally shown to mature to a significant degree of differentiation: the height of centrally located epithelial cells increased at least eight-fold over control values, tight junctions were established and three brush border enzymes became detectable. These results agree well with previous reports on endodermal development in organ cultures and in endoderm transplants in vivo. ${ }^{92122}$ The susceptibility of isolated endoderm to mesenchymal induction in vitro is high only during a short gestational period. Endoderm of the 14th day of gestation responds poorly to intestinal mesenchyme in vitro. After another 48 hours, the rate of already determined endodermal cells has increased abruptly. By the 16th day most fetal epithelial cells display 'self-differentiating' properties in vitro - that is, they acquire brush border enzyme activity even when cultured alone on plastic (own unpublished results). These endodermal cells will appear equally insensitive to different kinds of mesenchymes in vitro because of their intrinsically high enzyme values. Hence, for the experiments described here, the gestational age of the fetuses was carefully observed (only 15 day-embryos were used throughout). Furthermore, in order to avoid interassay variations, ' endoderm of the same litter was cocultured with the three types of mesenchyme in parallel.

Gastric mesenchyme, chosen as a control mesenchyme because of its close anatomical relationship to the small intestine, had been expected to yield less pronounced but essentially similar results. It did not, however, encourage epithelial maturation in the endodermal coculture system. Only one brush border enzyme, alkaline phosphatase, was detected in these coculture. The contrasting behaviour of gastric and intestinal mesenchyme in vitro supports the concept of regional specificity of the mesenchyme along the endodermal tube. ${ }^{3}$ This is in line with two recent descriptions of a difference in inductive potential between stomach and duodenal mesenchyme in vivo. ${ }^{2324}$ The conservation of regional specificity in vitro will allow for further investigation into the distinct local characteristics of gatrointestinal mesenchyme. This is particularly interesting in view of the known instability of the gastric epithelial phenotype in intestinal metaplasia. ${ }^{25}$

Skin derived mesenchyme had a profoundly different effect on endodermal cells compared to small intestinal mesenchyme. It induced a minor increase in alkaline phosphatase activity and no polarisation in the endodermal cells. A similar lack of potential when compared with intestinal mesenchyme was noted in previous studies using skin fibroblast cultures grafted under the kidney capsule of adult rats in combination with gizzard endoderm. ${ }^{9}$ In other studies, however, fetal rat skin fibroblasts were indeed claimed to be effective promoters of endodermal differentiation both in vivo and in vitro. ${ }^{13}$ ${ }^{26}$ Lack of promotional activity of skin fibroblasts in our study was not simply a sign of neutrality like that of a plastic surface since it was accompanied by a proliferation stimulus to the endodermal cells. The average endodermal colony size on skin mesenchyme was about two to three times greater than on intestinal mesenchyme. Increased proliferation in combination with maturation arrest is a common cellular event. In fact, proliferation and differentiation are deemed to be mutually exclusive decisions of undetermined cells. In the field of gastroenterology, for example, this concept has been applied to explain the syndrome of crypt cell hyperplasia associated with immature villus enterocytes of coeliac disease and tropical sprue. ${ }^{27}{ }^{28}$ Among the factors putatively modulating this process which have been discussed, ${ }^{29}$ those localised in the gut mucosa acting as paracrine factors should receive increasing attention. Noncirculating, tissue borne factors with short range efficiency may very well be involved. An intriguing example of short range (growth) factor-related activity of the small intestinal mesenchyme has recently been presented: fetal gut mesenchyme, but not pancreatic nor lung mesenchyme, specifically stimulated the growth of spinal cord nervous tissue when transplanted into its vicinity in mouse embryos. ${ }^{30}$ Our own observations concerning intestinal epithelial proliferation modulated by mesenchymal cells of different sources may be significant in this context. In fact, the suppression of the normal genetic program of the primary endoderm by heterologous mesenchyme may be even more noteworthy than its support by homologous mesenchyme because it points to the instability of that program at a particular developmental age. Whether there exist common causes for the proliferation increase and maturation arrest inflicted upon endodermal cells by skin mesenchyme in vitro and the lack of maturation associated with crypt cell hyperplasia in adaptation or disease, remains to be determined. 
Epithelial cell-cell interactions are a prerequisite for epithelial differentiation in vitro. Single cells never polarise. The differentiation-promoting effect of contact inhibition and tight junction formation are intrinsic qualities of the endoderm proper and should not be mistaken for a specific mesenchymal effect. In confluent epithelial monolayers on various substrates it is difficult to distinguish between intraepithelial cellular and mesenchymal-epithelial cellular interactions. ${ }^{13}$ Our experimental approach therefore attempted to avoid a confluent epithelial monolayer covering the mesenchyme. Growth and differentiation of the endoderm was determined in sparse individual endodermal cell colonies which did not coalesce to form a confluent monolayer. This implied that only the centre cells of the colonies became contact-inhibited. Indeed, endodermal differentiation on intestinal mesenchyme was always most pronounced in the centre and a gradient of cell density and cell height was formed to the periphery. On skin mesenchyme such a centre did not form in the colonies because the overriding effect of skin mesenchyme was to stimulate endodermal proliferation. Because colony expansion is smaller on fetal intestinal than on fetal skin mesenchyme, the promoting effect of homologous mesenchyme may have been related to growth inhibition. Colony expansion, however, is also restricted on gastric mesenchyme and on an albumin substrate which are as inefficient in inducing differentiation as skin mesenchyme. Inhibition of growth alone, therefore, cannot account for the differentiation promoting activity of the intestinal mesenchyme.

The activity of three brush border enzymes was closely correlated to the degree of maturation of the endoderm in vitro (Fig. 6 and Table). A most interesting observation was the detection of lactaseand alpha-glucosidase positive cells exclusively in endodermal colonies associated with intestinal mesenchyme treated with dexamethasone in the medium. Both brush border enzymes have been shown before to be highly glucocirticoid sensitive in organ cultures of fetal rat intestine..$^{22}$ Dexamethasone selectively inhibits DNA synthesis of upper crypt cells in organ culture, thereby reducing the proliferative compartment of the epithelium while the mitotic index of the stem cells remains unchanged..$^{22}$ The upper crypt cells are thus arrested sooner in the $G_{0}$-phase which is accompanied by a remkarable increase in ribosomal RNA and followed by the acceleration of brush border maturation. ${ }^{31}$ Cytosolic glucocorticoid receptors have been demonstrated in crypt cells. ${ }^{32}$ In this study, enterocytes sufficiently similar to crypt cells developed only in homologous cocultures so the influence of dexamethasone became apparent there. Thus, the enhancing effect of this hormone on brush border enzyme activity depends upon the status of the enterocytes - that is, the availability of receptors and the degree of cytodifferentiation, rather than on mesenchymal processing.

In conclusion, the significance of these results lies with the fact that we are able to identify striking variations in the response of fetal small intestinal epithelium to three types of mesenchyme. A sensitive, in vitro model is presented in which the small intestinal endoderm of a certain developmental age can be directed either towards proliferation or towards maturation through organspecific mesenchymal signals. The superiority of homologous mesenchyme over mesenchyme from other organs in promoting the differentiation of fetal intestinal epithelial cells is demonstrated. Ongoing stromalepithelial interactions have been substantiated in some adult organs. ${ }^{33}$ Further investigations should thus reveal whether inductive properties of the mesenchyme of the lamina propria can be traced in the adult intestinal mucosa.

We gratefully acknowledge the expert technical assistance of Brigitte Schneider and Doris Lazar. This work was supported by grant $\mathrm{Ri} 136 / 12-3$ of the Deutsche Forschungsgemeinschaft, Bonn-Bad Godesberg.

\section{References}

1 Grobstein C. Mechanisms of organogenetic tissue interaction. Natl Cancer Inst Monogr 1967; 26: 279-99.

2 Auerbach R. Morphogenetic interactions in the development of the mouse thymus gland. Dev Biol 1960; 2: $271-84$.

3 Smith BT, Fletcher WA. Pulmonary epithelialmesenchymal interactions: beyond organogenesis. Hum Pathol 1979; 10: 248-50.

4 Jamieson JD. Plasmalemmal glycoproteins and basal lamina: involvement in pancreatic morphogenesis. Prog Clin Biol Res 1982; 91: 413-27.

5 Kedinger M, Haffen K, Simon-Assman P. Control mechanisms in the ontogenesis of villus cells. In: Desnuelle $\mathrm{P}$, Sjostrom $\mathrm{H}$, Noren $\mathrm{O}$, eds. Molecular and cellular basis of digestion. Elsevier Sciences, 1986: 32535.

6 Rutter WJ. The development of the endocrine and exocrine pancreas. In: Fitzgerald PJ, Morrisson AB, eds. The pancreas. Baltimore: Williams and Wilkins, 1980: 30-8.

7 Kramer B, Andrew A, Rawdon BB, Becker P. The effect of pancreatic mesenchyme on the differentiation of endocrine cells from gastric endoderm. Development 1987; 100: 661-7.

8 Mathan M, Hermos JA, Trier JS. Structural features of the epithelio-mesenchymal interface of rat duodenal mucosa during development. J Cell Biol 1972; 52: 57788 . 
9 Haffen K, Lacroix B, Kedinger M. Simon-Assmann P. Inductive properties of fibroblastic cell cultures derived from rat intestinal mucosa on epithelial differentiation. Differentiation 1983; 23: 226-33.

10 Haffen K, Kedinger M, Simon-Assmann. Mesenchymedependent differentiation of epithelial progenitor cells in the gut. J Pediatr Gastroenterol Nutr 1987; 6: 14-23.

11 Hahn U, Schuppan D. Hahn EG, Merker H-J, Riecken E-O. Intestinal cells produce basement membrane proteins in vitro. Gut 1987; 28 [suppl]: 143-51.

12 Quaroni A. Development of fetal rat intestine in organ and monolayer culture. J Cell Biol 1985; 100: 1611-22.

13 Kedinger M, Simon-Assmann P. Alexandre E. Haffen $K$. Importance of a fibroblastic support for in vitro differentiation of intestinal endodermal cells and their response to glucocorticoids. Cell Differ 1987; 20: 17182.

14 Gutschmidt S, Lange U, Riecken E-O. In situmeasurements of protein contents in the brush border region along rat jujunal villi and their correlations with four enzyme activities. Histochemistry 1980; 72: 467-9.

15 Merker HJ, Barrach HJ. The morphology of basement membrane formation. Eur J Cell Biol 1981; 26: 111-20.

16 Quaroni A, Wands J, Trelstad RL, Isselbacher KJ. Epithelioid cell cultures from rat small intestine $J$ Cell Biol 1979; 80: 248-65.

17 Hahn U. Extracellular matrix proteins in small intestinal cell cultures. Scand J Gastroenterol. 1988: 23 (suppl 151): 70-8.

18 Rattner DW, Ito S, Rutten MJ, Silen W. A rapid method for culturing guinea pig gastric mucous cell monolayers. In Vitro 1985; 21: 453-62.

19 Doell RG, Kretchmer $\mathrm{H}$. Intestinal invertase: precocious development of activity after injection of hydrocortisone. Science 1964; 43: 42-4.

20) Moog F. The differentiation and redifferentiation of the intestinal epithelium and its brush border enzymes. In: Ciba Foundation Series 70. Development of mammalian absorptive processes. Amsterdam: Elscvier, 1979: 3150 .

21 Simon-Assman P, Kedinger M, Grenier JF, Haffen K. Control of brush border enzymes by dexamethasone in the fetal rat intestine cultured in vitro. $J$ Pediatr Gastroenterol Nutr 1982; 1: 257-65.
22 Beaulieu JF, Calvert R. Hormonal regulation of epithelial cell proliferation in the fetal mouse duodenum in vitro. Anat Rec 1987: 217: 250-5.

23 Ishizuya-Oka A. Mizuno T. Intestinal cytodifferentiation in vitro of chick stomach endoderm induced by the duodenal mesenchyme. J Embryo Exp Morph 1984; 82: 163-76.

24 Lacroix B, Kedinger M, Simon-Assmann PM, Haffen K. Effects of human fetal gastroenteric mesenchymal cells on some developmental aspects of animal gut endoderm. Differentiation 1984; 28: 129-35.

25 Morson BC. Precancerous lesions of the upper gastrointestinal tract. JAMA 1962; 179: 311-28.

26 Lacroix B, Kedinger M, Simon-Assmann P, Haffen K. Enzymatic response to glucocorticoids of the chick intestinal endoderm associated with various mesenchymal cell types. Biol Cell 1985; 54: 235-9.

27 Lipkin M. Proliferation and differentiation of normal and diseased gastrointestinal cells. In: Johnson LR, ed. Physiology of the gastrointestinal tract. New York: Raven Press. 1987, vol I: 255-85.

28 Mathan MM. Ponniah J, Mathan VI. Epithelial cell renewal and turnover and relationship to morphological abnormalitics in jejunal mucosa in tropical sprue. Dig Dis Sci 1986; 31: 586-92.

29 Johnson LR. Regulation of gastrointestinal growth. In: Johnson LR, ed. Physiology of the gastroinestinal tract. New York: Raven Press, 1987, vol I: 301-34.

30 Rothman T, Gershon MD, Fontaine-Perus JC, Chanconic M. LeDourain NM. The effect of backtransplants of the embryonic gut wall on growth of the neural tube. Dev Biol 1987; 124: 331-46.

31 Batt RM, Scott J. Response of the small intestinal mucosa to oral glucocorticoids. In: Polak J, Bloom SR, Wright NA, Daly MJ, eds. Structure of the gut. Glaxo Group Res Ltd, Herts: Wave, 1982: 391-405.

32 Lentze MJ. Coloney PC, Trier JS. Glucocorticoid receptors in isolated intestinal epithelial cells in rats. Am J Physiol 1985; 249: 58-65.

33 Cunha GR, Bigsby RM, Cooke PS, Sugimura Y. Stromal-epithelial interactions in adult organs. Cell Differentiation 1985; 17: 137-48. 